\title{
Relações entre Competência em Informação, Gestão Documental e Gestão da Informação Arquivística
}

\author{
Relationship between Information Literacy, Records Management and Archival Infor- \\ mation Management
}

\author{
Renata Lira Furtado \\ Doutora em Ciência da Informação \\ Universidade Federal do Pará \\ renatalira@ufpa.br \\ Lucas Thery Monte Verde Silva \\ Mestrando em Ciência da Informação \\ Universidade Federal do Pará \\ delsmv@gmail.com
}

\section{Resumo}

A partir das discussões pós-modernas relacionadas ao atual paradigma arquivístico e da inserção da competência em informação na atuação do arquivista, surge o questionamento a ser respondido nesta pesquisa a partir do objetivo de identificar os elementos da competência em informação relevantes ao arquivista frente à gestão da informação arquivística. Nesse contexto, desenvolveu-se uma pesquisa bibliográfica, acerca das temáticas: gestão documental, gestão da informação arquivística e competência em informação - apoiada na análise comparativa. Como resultados, apresentou-se quatro tipos de relações: relações históricas; relações a partir do usuário; relações a partir do arquivista; e relações a partir da gestão da informação arquivística, subdividida nas relações: alicerces e dimensões e habilidades e as atividades/funções.

\section{Palavras-Chave}

Competência em Informação. Gestão da Informação Arquivística. Gestão Documental. Arquivista.

\begin{abstract}
From the post-modern discussions related to the current archival paradigm and the insertion of information literacy in the performance of the archivist, the question arises, aimed at this research, to identify which elements of Information Literacy are relevant to the archivist in relation to archival information management. In this context, this research was developed through bibliographic research, on the themes: records management, archival information management and information literacy - supported by comparative analysis. As a result, four types of relationships were presented: historical relationships; relations from the user; relationships from the archivist; and relations based on archival information management, subdivided into relationships: foundations and dimensions and skills and activities/functions.
\end{abstract}

\section{Keywords}

Information Literacy. Archival Information Management. Records Management. Archivist. 


\section{INTRODUÇÃO}

A competência em informação (Colnfo) surgiu da necessidade de instruir os indivíduos para um melhor aproveitamento informacional, ou seja, habilidades para o reconhecimento e uso da informação, visando à solução de problemas e tomadas de decisão (DUDZIAK, 2003). Em sua origem, o objetivo da Colnfo era qualificar os usuários, melhorando a forma de recuperação da informação dentro das bibliotecas.

As discussões acerca da Colnfo foram incorporadas ao universo da Ciência da Informação e atualmente estão inseridas também no contexto arquivístico, com pesquisas que visam investigar a produção bibliográfica em torno da díade Arquivologia - Colnfo (FURTADO; BELLUZZO; PAZIN, 2016; FURTADO; BELLUZZO; PAZIN, 2018); a Colnfo na formação do arquivista (FARIAS; FURTADO, 2020; FURTADO; FERREIRA, 2019; FURTADO; BELLUZZO; PAZIN, 2019a; FURTADO; BELLUZZO; PAZIN, 2017; MARTENDAL; SILVA; VITORINO, 2017); a competência em informação, desinformação e fake news no cenário arquivístico (MOURA; FURTADO, 2019); as pesquisas desenvolvidas em torno da díade Colnfo - Arquivologia (FURTADO; BELLUZZO; PAZIN, 2019b; FURTADO; BELLUZZO; PAZIN, 2019c).

Dentre essas pesquisas destacam-se ainda aquelas que relacionam a Colnfo com a atuação profissional do arquivista (FURTADO; SILVA, 2019; SILVA et al., 2019; FURTADO; BELLUZZO, 2018; VENTURA; SILVA; VITORINO, 2018) e nesse contexto é possível inserir a atuação do arquivista nos processos de gestão documental, cenário de desenvolvimento deste estudo.

A gestão documental configura-se como um conjunto de fazeres relevantes em meio à gama de atividades desenvolvidas pelo arquivista. Os documentos, elementos chave nesse processo, são produzidos, recebidos e acumulados a todo momento, seja por entidades públicas ou privadas, ou ainda em ambientes familiares e no contexto pessoal. São geridos e preservados para subsidiar tomadas de decisão, comprovações de direitos coletivos e individuais, dentre outras funções (BERNARDES; DELATORRE, 2008).

Entretanto, a partir da visão pós-moderna proposta por Terry Cook (2012), o objeto de estudo da Arquivologia se desprende da materialidade física - o suporte, e concentra-se na informação arquivística, conceituada como um conjunto estruturado de representações factuais advindas das atividades realizadas por pessoa física ou jurídica, no exercício de sua função e registradas em documentos de arquivo (CALDERON, 2011, p.109).

No contexto da informação arquivística, o termo gestão documental parece não ser mais adequado, abrindo espaço para a expressão gestão da informação arquivística. Deste modo, é possível afirmar que durante o planejamento e o desenvolvimento da gestão da informação arquivística, o arquivista necessitará dispor de habilidades para lidar com a informação, visando aperfeiçoar a compreensão do fluxo informacional para melhor geri-lo.

Assim, o objetivo da presente pesquisa é identificar quais os elementos da Colnfo são relevantes ao arquivista na elaboração e desenvolvimento da gestão da informação arquivística.

A justificativa deste estudo desdobra-se da apreciação de uma recente corrente de pesquisadores que constituem o Grupo de pesquisa Arquivologia e competência em informação (GPArqColnfo) da Faculdade de Arquivologia (FAARQ) da Universidade Federal do Pará (UFPA), que visa desenvolver pesquisas relacionadas à Colnfo aplicada à Arquivologia e à profissão do arquivista, em específico a "Linha de Pesquisa 2 - Competência em informação e o fazer arquivístico". Tais inferências reafirmam as questões pós-modernas emergen- 
tes na arquivística, agregando valor ao profissional a partir das habilidades com a informação.

\section{PROCEDIMENTOS METODOLÓGICOS}

Para a construção do referencial teórico, recorreu-se à pesquisa bibliográfica realizada nas bases de dados: Google Scholar, Base de Dados em Ciência da Informação (BRAPCI), Portal de Periódicos da Coordenação de Aperfeiçoamento de Pessoal de Nível Superior (CAPES); em periódicos científicos da Arquivologia e Ciência da Informação e nos anais dos eventos: Encontro Nacional de Pesquisa em Ciência da Informação (ENANCIB) e Congresso Nacional de Arquivologia (CNA).

Os termos utilizados na pesquisa bibliográfica foram: documento arquivístico, informação arquivística, gestão de documentos, gestão da informação arquivística, e competência em informação. Não houve recorte cronológico, considerando o intuito de recuperar referências que possibilitassem traçar paralelos entre as temáticas desde suas respectivas origens na literatura. Não foi estabelecida delimitação acerca dos idiomas, buscou-se inicialmente os termos em português (PT-BR) e estes direcionaram para referências em outros idiomas como inglês (ING) e espanhol (ESP).

Para análise dos resultados, optou-se pela análise comparativa, onde é possível identificar semelhanças, diferenças e, a partir disso, constituir modelos (SCHNEIDER, 1998; FACHIN, 2003). O método de análise comparativa foi utilizado com o intuito de identificar os preceitos da competência em informação no referencial teórico da gestão documental e da gestão da informação arquivística, especialmente, nas ações de planejamento e desenvolvimento de atividades de uso e tratamento da informação, visando reconhecer as habilidades necessárias ao arquivista nesse contexto.

\section{GESTÃO DA INFORMAÇÃO ARQUIVÍSTICA: DO RECORDS MANAGEMENT À CONTEMPO- RANEIDADE}

Após a Segunda Guerra Mundial (1939-1945), em decorrência do progresso científico e tecnológico na sociedade, a produção documental foi elevada, extrapolando a capacidade de custódia e controle das instituições, resultando em um grande volume de massa documental, induzindo-as à busca de soluções para gerir tais documentos.

Segundo Sousa (2007), os métodos de tratamento dos documentos até então existentes eram suficientes para responder às necessidades das organizações. Com o aumento do volume documental, surgiu outra realidade que exigiu novos métodos e possibilidades, como as comissões governamentais nos Estados Unidos da América (EUA), que visavam encontrar soluções para melhoria no uso dos documentos no âmbito da administração pública (JARDIM,1987). Assim, a Comissão Hoover (1947) atuou com uma série de atividades, que analisava quais os procedimentos técnicos iriam reduzir o volume documental e identificálos para melhor armazená-los, bem como ações de educação continuada.

Inicialmente, a gestão documental, tradução utilizada para o termo original records management, foi constituída sob um olhar mais econômico e administrativo do que propriamente arquivístico, racionalizando a produção documental e o prazo de guarda (INDOLFO, 2007). Cabe ressaltar que os EUA foram os percussores deste modelo, datado de 1940 e que mais tarde, com a aprovação da Lei Federal de Arquivos em 1950 se caracterizaria um marco de institucionalização da gestão documental nos EUA. 
Além de institucionalizar, a lei determinou em sua redação a criação de um programa de gestão documental a ser implementado pelos órgãos governamentais. Ainda na década de 50, a criação do Conselho Internacional de Arquivos (CIA) vinculado a Organização das Nações Unidas para a Educação, Ciência e Cultura (UNESCO), instituído no I Congresso Internacional de Arquivos, em agosto de 1950, na capital francesa, que, segundo Santos (2010), tinha como maior tarefa a cooperação e o estabelecimento de consensos quanto aos conceitos e métodos de trabalho, portanto, ambos exercem papéis significativos na edificação da gestão documental.

A UNESCO desenvolveu o programa Records and Archives Management Program (RAMP) para que fosse apresentado a importância dos documentos e arquivos para o público em geral e tomadores de decisão e nortear o planejamento e execução da gestão de documentos nos governos. As fases básicas da gestão documental reconhecida por Rhoads (1983), em seu trabalho intitulado La Función de la gestión de documentos y archivos en los sistemas nacionales de información: un estudio del RAMP, são: produção, utilização, conservação e destinação. As fases descritas, em uma linha de execução, compreendem a "vida" dos documentos.

Barros (2010) explica que nesse cenário, Schellenberg e Posner difundem a metáfora do "Ciclo vital dos documentos" que será absorvida junto À "Teoria das três idades", junção proposta por Rousseau e Couture (1998) em que o documento passará entre as fases corrente, intermediária e permanente de acordo com sua frequência de utilização e de que forma se dá sua utilização, mas não necessariamente na ordem disposta.

No que concerne às conceituações na literatura arquivística, o uso de diferentes definições (contexto e tempo) acerca da gestão documental se faz necessário, “[...] pois sua epistemologia foi se renovando e desdobrando entre os autores que procuravam fundamentos para seus estudos, pesquisas e atuação profissional." (INDOLFO, 2007). Para Jardim (1987), a gestão cobre todo o ciclo de existência dos documentos desde sua produção até eliminação ou recolhimento para guarda permanente, ou seja, trata-se de todas as atividades inerentes às idades corrente e intermediária. Numa perspectiva mais recente, Vitoriano (2017a) entende que a gestão documental é a etapa em que documentos administrativos são organizados, classificados, avaliados e descritos, de modo a garantir o cumprimento de seu ciclo de vida até a fase em que deverá ser eliminado ou destinado à preservação permanente.

A definição da gestão documental, no primeiro momento, é descrita pelos autores de forma equivalente, salientando a abrangência da gestão nas fases e idades dos documentos, buscando a racionalização como forma de se evitar massas documentais acumuladas e a preservação dos documentos de valor histórico para difusão. Ao longo do tempo, as pesquisas começam a modificar a conceituação, levando em consideração a mudança de paradigma, as novas formas de registro da informação e armazenamento.

No Brasil, a Lei $n^{\circ} 8.159$, de 8 de janeiro de 1991, dispõe sobre a Política Nacional de Arquivos e define gestão documental como "[...] conjunto de procedimentos e operações técnicas referentes à sua produção, tramitação, uso, avaliação, e arquivamento em fase corrente e intermediária, visando a sua eliminação ou recolhimento para a guarda permanente." (BRASIL, 1991). Ao analisarmos a definição apresentada na legislação, subentende-se que a gestão documental se inicia na produção e finaliza na destinação (eliminação ou recoIhimento) não abrangendo as funções arquivísticas exercidas também nos documentos custodiados em fase permanente, o que descaracteriza o objetivo da Arquivologia para com a sociedade, que é disponibilizar a informação. 
A gestão documental no âmbito arquivístico brasileiro desenvolveu-se sob a influência das correntes arquivísticas de outros países, embasadas nas atividades e funções que integram o processo: diagnóstico, identificação, classificação, avaliação, descrição, conservação e preservação, e difusão. Os conceitos de tais atividades e funções, serão brevemente apresentados, a fim de subsidiar as discussões e os resultados desse estudo.

- Diagnóstico - análise das informações básicas - quantidade, localização, estado físico, condições de armazenamento, grau de crescimento, frequência de consulta e outras sobre arquivos (CAMARGO; BELLOTTO, 1996). Braga e Roncaglio (2019) destacam que a palavra "análise" na definição apresentada evidencia um sentido próprio para a definição de "diagnóstico de arquivo", considerando que "diagnóstico" não se trata da busca, da pesquisa, do processo de coleta e sim da análise das informações já coletadas. Ferreira e Melo (2008) definem que a elaboração do diagnóstico é o primeiro passo para se alcançar uma gestão documental e, também, que os arquivos correspondem à verdadeira necessidade de informação de seu produtor. Nesse contexto, compreende-se que o diagnóstico tem a finalidade de buscar informações acerca da entidade produtora, entender a relação de seus documentos com o contexto que os gerou e suas necessidades específicas.

- Identificação - metodologia de influência espanhola que se configura como uma fase de levantamentos de dados que estuda analiticamente o documento e os vínculos que mantém com o órgão produtor. É uma metodologia que busca investigar as estruturas administrativas, as funções e os documentos como produto que constituirão as séries documentais e fundos arquivísticos e atribuir-lhes uma identidade (RODRIGUES, 2011, p.119). No que tange à importância desta atividade, "A identificação arquivística é imprescindível como parâmetro para o desenvolvimento de procedimentos normativos para a racionalização da produção, tramitação, classificação, avaliação, acesso e uso dos documentos." (BUENO, 2011, p.13).

- Classificação - é uma "[...] função importante para a transparência e o compartiIhamento de informações, que são caminhos seguros para a tomada de decisão, para a preservação da memória técnica e administrativa das organizações contemporâneas e para o pleno exercício da cidadania." (SOUSA, 2003, p.1). Duas visões permeiam a classificação, uma consiste na questão intelectual de organização dos arquivos, que visa a elaboração de um instrumento, baseado em seus organismos, funções, atividades, dentre outros critérios, agrupados por suas semelhanças ou diferenças e a outra relacionada à técnica de interpretação do documento para a atribuição da classe, codificação e ordenação, de acordo com o instrumento elaborado (FARIA, 2006).

- Avaliação - configura-se como um processo de análise e seleção de documentos que visa estabelecer os prazos de guarda e a destinação final dos documentos, definindo quais serão preservados para fins administrativos ou de pesquisa (INDOLFO, 2012).

- Descrição Arquivística - é definida como "[...] atividade que visa representar conjuntos documentais em arquivos, identificando e explicando o contexto de produção, conteúdo e características inerentes aos documentos, a fim de facilitar a localização e o acesso." (VITAL et al., 2019, p.31). Para que seja desenvolvido o processo de descrição, é preciso reunir informações, principalmente além das já registradas e reconhecidas nos documentos, um trabalho de pesquisa que consiste em buscar respaldo em fontes diversas (VITAL et al., 2019).

- Preservação e Conservação - políticas de preservação e as práticas de conservação são de vital importância no processo de gestão arquivística. Preservação configura-se como um conjunto de medidas e estratégias administrativa, política e operacional que contribuem 
para a preservação da integridade dos materiais, enquanto conservação é um conjunto de ações estabilizadoras que visam desacelerar o processo de degradação de documentos ou objetos, por meio de controle ambiental e de tratamentos específicos (CASSARES, 2000).

- Difusão - consiste na "[...] busca de estratégias que visem à acessibilidade (facilitar o acesso, procurar vencer as barreiras tecnológicas e linguísticas), transparência (tornar público), atingir determinado público (através do marketing e demais ferramentas auxiliares)." (ROCKEMBACH, 2015). Martendal (2017) enfatiza que a difusão pode ocorrer em todo o ciclo vital dos documentos, de forma diferenciada, a partir de cada necessidade correspondente à fase ao qual o grupo de informações pertence e que o seu foco é o público, tendo como base a necessidade informacional para sua elaboração. As atividades e funções mencionadas possuem como finalidade garantir o uso das informações registradas a longo prazo, construção e perpetuação da memória, no entanto, se faz necessário utilizar-se da difusão arquivística, a fim de que o resultado do processo de gestão não seja uma fonte de informação represada e desconhecida.

Analisando as definições das atividades exercidas em cada função arquivística, que integram a gestão documental, é evidente que há um direcionamento ao documento como objeto, automaticamente condicionando a atender às características e estruturas que efetivam um documento arquivístico. No entanto, a mudança do objeto de estudo da Arquivologia proposta pela teoria pós-moderna de Terry Cook (2012) traz novas discussões em torno da pesquisa e das práticas arquivísticas, logo, se faz necessário entender a diferença entre os objetos: documento arquivístico e informação arquivística.

O documento na visão de Otlet (1937) é a informação registrada em um suporte que possa ser acessada, "[...] é o livro, a revista, o jornal, é a peça de arquivo, a estampa, a fotografia [...]". Nesse contexto, qual o fator que caracteriza o documento como sendo arquivístico? Tal característica se dá, de acordo com Paes (2004), pela produção ou recebimento por uma entidade, pública ou privada, e por pessoas físicas, munida de elementos informativos ou de prova, provindos do exercício de suas atividades e funções. Isso ressalta a relação orgânica entre o documento e o produtor.

Bellotto (2006), Rondinelli (2011) e Formiga (2017) apresentam outras características como: resultado de um processo jurídico e administrativo, trata-se de exemplares únicos e com uma gama variada de formas e suportes, e que estejam de acordo com os princípios arquivísticos (unicidade, organicidade, indivisibilidade, integridade e autenticidade).

O documento é fruto da necessidade da sociedade humana, logo, as mudanças ocasionadas pelo progresso científico e tecnológico afetaram diretamente na forma de se registrar a informação e o suporte utilizado, influenciado principalmente pelo surgimento do universo informacional que aumentou a velocidade da produção e tramitação das informações. Nesse contexto, surgem os documentos eletrônicos (CALDERON, 2011). No entanto, Cook (2012) explica que o documento deixa de ser um objeto físico e passa a ser um objeto conceitual de informação, controlado por metadados, que, com apenas um clique, combinam contexto, conteúdo e estrutura, transformando-o de uma percepção passiva e fixa, para um papel ativo e dinâmico.

Quanto à expressão "informação arquivística", trata-se de uma criação da escola canadense de Arquivologia, que emerge impulsionada pela explosão informacional no século $X X$, no qual se originam os sistemas informatizados de registro de informações (TORRES, 2019). Para melhor compreendê-la, precisa-se retirar o foco da materialidade, que, de acordo Tognoli (2012), é a transição do estudo do documento de arquivo para a informação or- 
gânica registrada, e, assim, compreende-se que a informação contida no documento se torna o novo foco.

Moreno (2007) explica o diferencial da informação arquivística em relação à informação de outra natureza:

[...] é que ela é produto das atividades de determinado organismo. Ou seja, ela é produzida dentro do contexto do exercício das funções/objetivos a que se propõem as entidades. Desta forma, está se tentando definir uma informação que apresenta como características básicas, estar registrada em um determinado suporte e ser o resultado das ações e transações da organização. Esse tipo específico de informação recebe a qualificação de orgânica, por guardar entre si as mesmas relações que se formam entre as competências e atividades das organizações, sejam públicas ou privadas. (MORENO, 2007, p.16).

Assim, compreende-se que a informação arquivística precede o documento, resultado das ações dos organismos, que posteriormente constituirão, ao serem agrupadas e codificadas em documentos de arquivo. Corroborando com a ideia de que a informação registrada e o suporte não são mais inseparáveis, segundo Vitoriano (2017b).

No cenário atual, onde as organizações se utilizam de tecnologias avançadas para registrar e armazenar as informações provindas de suas funções, questões como essa provocam o campo de pesquisa da Arquivologia a atualização e desenvolvimento das práticas arquivísticas, para atender ao objetivo de gerir e disponibilizar a informação arquivística.

Com isso, a expressão "gestão da informação arquivística" começa a ser apresentada e definida como "[...] políticas que possibilitam o tratamento das informações desde a sua produção até a sua destinação final, permitindo, assim, que estejam organizadas sistematicamente, acessíveis e controladas." (NASCIMENTO; FLORES, 2007).

Nascimento e Flores (2007) ressaltam que gerenciar a informação arquivística coloca a Arquivologia no ambiente de qualidade organizacional que almeja excelência nos produtos e serviços dispostos, ratifica sua importância junto à sociedade, amplia o espaço de atuação do arquivista e mais uma forma de consolidação profissional. A priori, o conceito atende à perspectiva da mudança do objeto da Arquivologia, entretanto, os autores citam as funções arquivísticas que integram a gestão documental: classificação de documentos e avaliação de documentos como procedimentos que "concretizam" a gestão da informação arquivística, a tornando uma evolução das práticas de gerenciamento na Arquivologia, ou seja, a gestão da informação arquivística é um aprimoramento da gestão documental.

Nesse prisma, para efeito desta pesquisa, será utilizada a expressão gestão da informação arquivística conforme apresentada na literatura, como sendo uma atualização da gestão documental que inclui a informação arquivística junto ao gerenciamento dos documentos arquivísticos.

Diante disso, quais as habilidades que o arquivista precisará desenvolver para atuar frente a essa questão contemporânea, em um ambiente de informações arquivísticas e documentos arquivísticos, no looping do progresso das Tecnologias de Informação e Comunicação (TICS)?

$\mathrm{Na}$ busca de possíveis respostas para este questionamento, a Colnfo se apresenta pertinente, pois devido às suas discussões acerca do uso estratégico da informação, dos recursos, sistemas e tecnologias que almejam a solução de problemas do cotidiano, atualização de princípios e práticas de gestão informacional que contribuem para a inovação e desenvolvimento social. (BELLUZZO et al., 2013). 


\section{COMPETÊNCIA EM INFORMAÇÃO}

O termo Information Literacy, que no Brasil consolidou-se como Competência em Informação, tem sua origem associada ao relatório The information service environment relationships and priorities. apresentado por Paul Zurkowski em 1974 à National Commission on Libraries and Information Science (NCLIS). O documento foi concebido tendo como fundamento as mudanças sociais influenciadas pelo desenvolvimento tecnológico e a constatação de que os cidadãos americanos não possuíam as habilidades para utilizar os recursos tecnológicos disponíveis e que viessem a ser desenvolvidos e apresentava como principal objetivo instruir a população para lidar com a abundância de informações disponíveis que excedem à capacidade humana de avaliar, com a diversidade de procedimentos de busca de informação existentes e com a variedade de rotas de acesso e fontes informacionais mal compreendidas e subutilizadas (FURTADO, 2019).

O referido relatório tem sido há décadas a única referência relacionada ao surgimento do termo. Contudo, Dudziak (2016) apresenta uma leitura sistematizada dos antecedentes e do contexto em que o termo Information Literacy surgiu. A autora construiu por meio de documentos, o percurso histórico, desde a trajetória social, econômica e política, que antecede o aparecimento do relatório apresentado por Zurkowski e que conduziu ao estabelecimento de um regime de informação que, consequentemente, resultou na proposição de políticas informacionais, que antecederam às próprias políticas de Colnfo.

Segundo Dudziak (2016), durante as décadas de 1960 e 1970, ainda persistiam os problemas relacionados às informações governamentais nos EUA, resquícios do contexto da depressão econômica e da guerra durante a primeira metade do século XX. Com isso, o Gabinete do Orçamento realizou uma avaliação das práticas de gerenciamento da informação em conjunto com 25 agências federais, resultando, após a análise, na recomendação de simplificação dos relatórios.

Neste contexto, Forest Wood Horton Jr., com experiência em várias agências governamentais, inclusive no exército americano, assumiu a Comissão de Avaliação dos Papéis Federais e identificou que as questões que envolviam a gestão da informação e o reconhecimento de seu custo e valor suscitavam preocupações. Outra observação apontada foi que a sociedade não estava disposta a custear bens e serviços de informação, considerando que a maioria dessas pessoas não aprenderam na escola ou no trabalho como lidar com a informação de forma eficiente e eficaz e não entendiam o porquê do alto valor atribuído à informação (DUDZIAK, 2016).

O estado estudava formas de incentivo à população por meio da redução de encargos, o desenvolvimento de um conceito que resultaria no planejamento, gerenciamento e controle da informação como um recurso organizacional. Na contramão, a sociedade hesitava financiar bens e serviços de informação e existia uma lacuna quanto ao uso da informação de forma eficiente e eficaz. Em 1971 Forest Wood Horton Jr. passa a ser consultor independente da Information Industry Association onde Paul Zurkowski atua como presidente e ambos passam a desenvolver atividades em conjunto, dentre elas o relatório já mencionado.

Em 1976 o conceito de Colnfo foi ampliado, incluiu-se as habilidades e os conhecimentos para localizar e utilizar informações com a tomada de decisões e a resolução de problemas. Cees J. Hamelink (1976) em seu artigo An alternative to News reforçava a necessidade de criar um programa de Colnfo e Owens (1976) em artigo intitulado State Governmentand Libraries destaca a importância da Colnfo para a democracia (DUDZIAK, 2016; FURTADO, 2019). 
O desenvolvimento da Colnfo, desde a década de 1980 até à contemporaneidade, está pautado inicialmente na popularização da expressão Information Literacy, na capacitação ao uso das TICs e em programas educacionais relacionados à "Sociedade da Aprendizagem". Num segundo momento, ainda de desenvolvimento, inicia-se a discussão e posterior inserção da Information Literacy nos currículos escolares americanos como disciplina básica. A consolidação se dá paralelamente ao desenvolvimento de outras frentes de atuação, como os programas educacionais em ambiente universitário. Em 1989 a American Library Association (ALA) apresenta o relatório Presential Committe on Information Literacy: Final Report reconhecendo a importância desta área para a manutenção de uma sociedade democrática e ressaltando a importância da Information Literacy para indivíduos, trabalhadores e cidadãos, reforçando o papel da informação na resolução de problemas e tomada de decisão. 0 ano de 1990 foi eleito como o International Literacy Year pela Assembleia Geral das Nações Unidas para marcar o início de uma década de esforços em prol da redução do analfabetismo (FURTADO, 2019).

O início do milênio é marcado pela participação ativa das instituições internacionais ligadas à Colnfo como a ALA, a IFLA e a UNESCO, num movimento de cooperação para a promoção de eventos internacionais e, consequentemente, declarações e manifestos, produto destes eventos, com reflexões, recomendações, ações e estratégias, para difusão e institucionalização da Colnfo em esferas locais, regionais, nacionais e mundial (FURTADO, 2019).

A Colnfo foi e tem sido inserida no campo de pesquisa da Ciência da Informação (Cl), pois ambas trabalham com questões voltadas ao uso da informação. Furtado (2019) destaca que os estudos sobre Colnfo, no Brasil, evidenciam questões que envolvem a mídia, a cidadania, a tecnologia, a educação e, mais recentemente, o universo organizacional, fatores e ambientes que aproximam os indivíduos comuns à área de estudo restrita até pouco tempo ao âmbito científico e acadêmico. Visão corroborada por Belluzzo (2004) que destaca que a Colnfo não é útil apenas em atividades acadêmicas e escolares, mas aplicáveis a todas as situações de resolução de problemas ligados à necessidade de informação.

Em relação à inserção da Colnfo no âmbito arquivístico, considera-se um cenário recente, são pesquisas desenvolvidas a partir de 2016 e que buscam dentre outras abordagens compreender o uso da informação arquivística, o papel do arquivista na sociedade contemporânea, bem como as habilidades necessárias para sua atuação nesse contexto, os fenômenos informacionais do século XXI, entre outros.

Furtado (2019) desenvolveu "Dimensões conceituais para a inserção da Competência em Informação no cenário arquivístico Brasileiro" com a intenção de que atuem como o embasamento teórico-conceitual para que os preceitos da Colnfo sejam inseridos no âmbito da Arquivologia, não apenas no eixo da formação profissional, mas que possa refletir na atuação profissional do arquivista, na construção de um arcabouço teórico relevante que atenda tanto ao universo acadêmico-científico, como das demais disciplinas que estabelecem relações com a Arquivologia e principalmente possa ser refletida em ações concretas que beneficiem a sociedade como um todo. São cinco dimensões apresentadas: 1 - Informação e conhecimento; 2 - Competência em informação; 3 - Sociedade; 4 - Universidade; e 5 - Arquivologia. A "Dimensão 5 - Arquivologia" destaca a tríade Arquivologia - Arquivo - Arquivista, onde em uma relação transdisciplinar a Colnfo permeia a formação profissional, refletindo nos métodos e práticas exercidas pelo arquivista. A autora destaca os elementos preceituais nessa relação: criatividade, inovação, pensamento lógico, criticidade, autonomia, liderança, 
proficiência investigativa, intuição, postura ética, capacidade de resolução de problemas (FURTADO, 2019).

Segundo Ferreira (2018), a Colnfo tem dentre seus principais alicerces "[...] identificar uma necessidade de informação, saber localizar a informação, compreender e analisar criticamente uma informação, a partir disso utilizar a informação de forma estratégica para propor soluções e disseminá-las.". O desenvolvimento destas habilidades poderá tornar o arquivista competente em informação, considerando que a Colnfo é uma ferramenta de aprendizagem essencial para a formação e o desenvolvimento do arquivista.

\section{A RELAÇÃO ENTRE COMPETÊNCIA EM INFORMAÇÃO E A GESTÃO DA INFORMAÇÃO AR- QUIVÍSTICA}

Embasado no referencial teórico apresentado acerca da gestão documental, da gestão da informação arquivística e da Colnfo, a partir da aplicação do método comparativo, foi possível estabelecer quatro relações abordando especificamente: o contexto histórico no qual emergiram, o usuário da informação arquivística disponibilizada, a atuação do arquivista e o processo da gestão da informação arquivística como um todo.

\section{Relações Históricas}

A evolução tecnológica e informacional, no período da Guerra Fria nos EUA, impulsionou o desenvolvimento de várias teorias e atividades que pudessem capacitar a sociedade para uso dessas ferramentas e controlar as informações registradas.

O Records Management e a Information Literacy surgem do mesmo contexto, as questões acerca das TICs, enquanto uma era voltada à administração da grande massa de informação registrada acumulada, a outra desenvolvia as questões de capacitação do uso das TICs para a solução de problemas, por meio do acesso e uso da informação que ela propicia. Porém, as duas teorias surgem e seguem paralelamente, devido à sua absorção em áreas do conhecimento diferentes, a Arquivologia e a Biblioteconomia.

O relatório, considerado o marco inicial da Colnfo, foi fruto do trabalho de profissionais da informação como: Horton Jr., que trabalhou na Divisão de Processamento de Dados/Informações Federais dos EUA, desenvolvendo atividades de gestão das informações produzidas a partir das atividades do governo estadunidense e do bibliotecário Paul Zurkowski.

Nesse contexto, foi possível evidenciar a relação das práticas arquivísticas como insumo base para a elaboração do relatório, pois a mencionada Divisão surgiu como uma ferramenta de gerenciamento de documentos e informações que vinham ocasionando problemáticas pontuais, como a acumulação, a organização e a transparência. Após isso, Forest Wood Horton Jr. passa a ser consultor da Information Industry Association presidida por Zurkowski, entidade essa que é definida como provedora do relatório (DUDZIAK, 2016).

Partindo deste pressuposto, Furtado (2019) ratifica essa evidência sobre o contexto que envolve os pressupostos do relatório e pontua a gestão de documentos e da informação junto às políticas públicas de acesso à informação, que foram acentuadas nas décadas de 1960 e 1970 nos EUA. 


\section{Relações a partir do usuário}

Para além das relações históricas, no processo de tratamento e disponibilização da informação, a gestão da informação arquivística tem por finalidade garantir o acesso à informação de forma eficaz, garantindo que essa informação possa ser utilizada, tanto pelo seu produtor, quanto pela sociedade em geral. Quanto ao uso eficiente da informação, nesse contexto a Colnfo se apropria dessa premissa, visando um melhor aproveitamento do produto da gestão da informação arquivística.

A relação disposta na Figura 1 se assemelha ao início dos estudos de Colnfo na Biblioteconomia. A relação disposta parte do produto da gestão da informação arquivística, a informação arquivística tratada, disponibilizada para o usuário, que utilizando-se da Colnfo poderá otimizar seu aproveitamento informacional. Porém, para que efetivamente haja a disponibilização da informação arquivística, se faz necessário possuir habilidades para utilizar a informação nos processos que culminam nesse acesso.

Figura 1 - Relações "usuário e competência em informação"

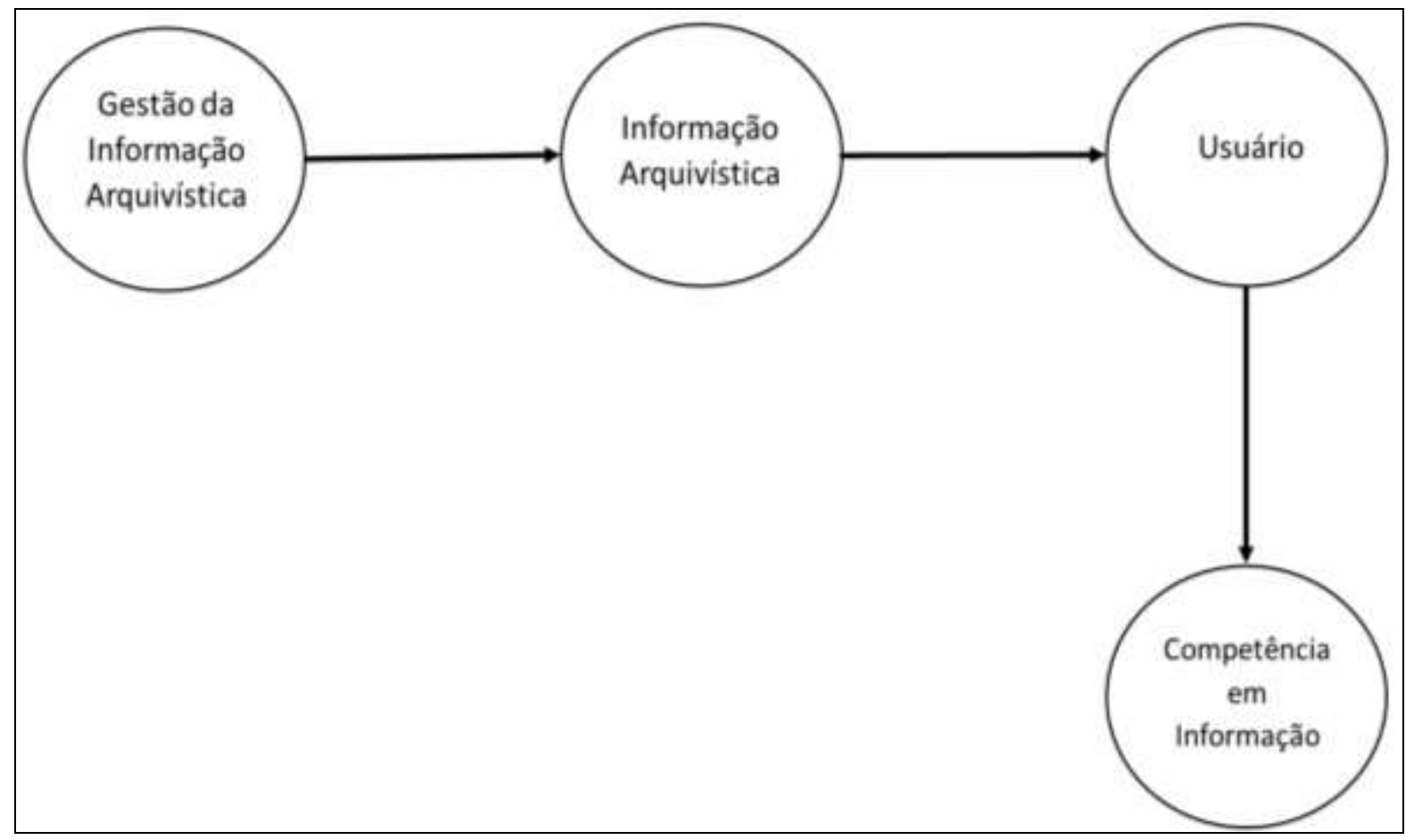

Fonte: Elaborado pelos autores (2020).

\section{Relações a partir do arquivista}

A Figura 2 elucida outro prisma relacional da Colnfo no âmbito arquivístico. Nesse processo, a Colnfo passa a ser desenvolvida pelo arquivista, visto que a gestão da informação arquivística é uma prática arquivística e ele é o profissional capacitado para planejá-la e desenvolvê-la. Tal relação é possível, pois tratar, organizar, controlar, disponibilizar e disseminar a informação arquivística, configuram uso de informação, onde utilizar-se das habilidades que torna esse uso eficiente, resultará em uma gestão da informação arquivística eficaz. 
Figura 2 - Relações "arquivista e competência em informação"

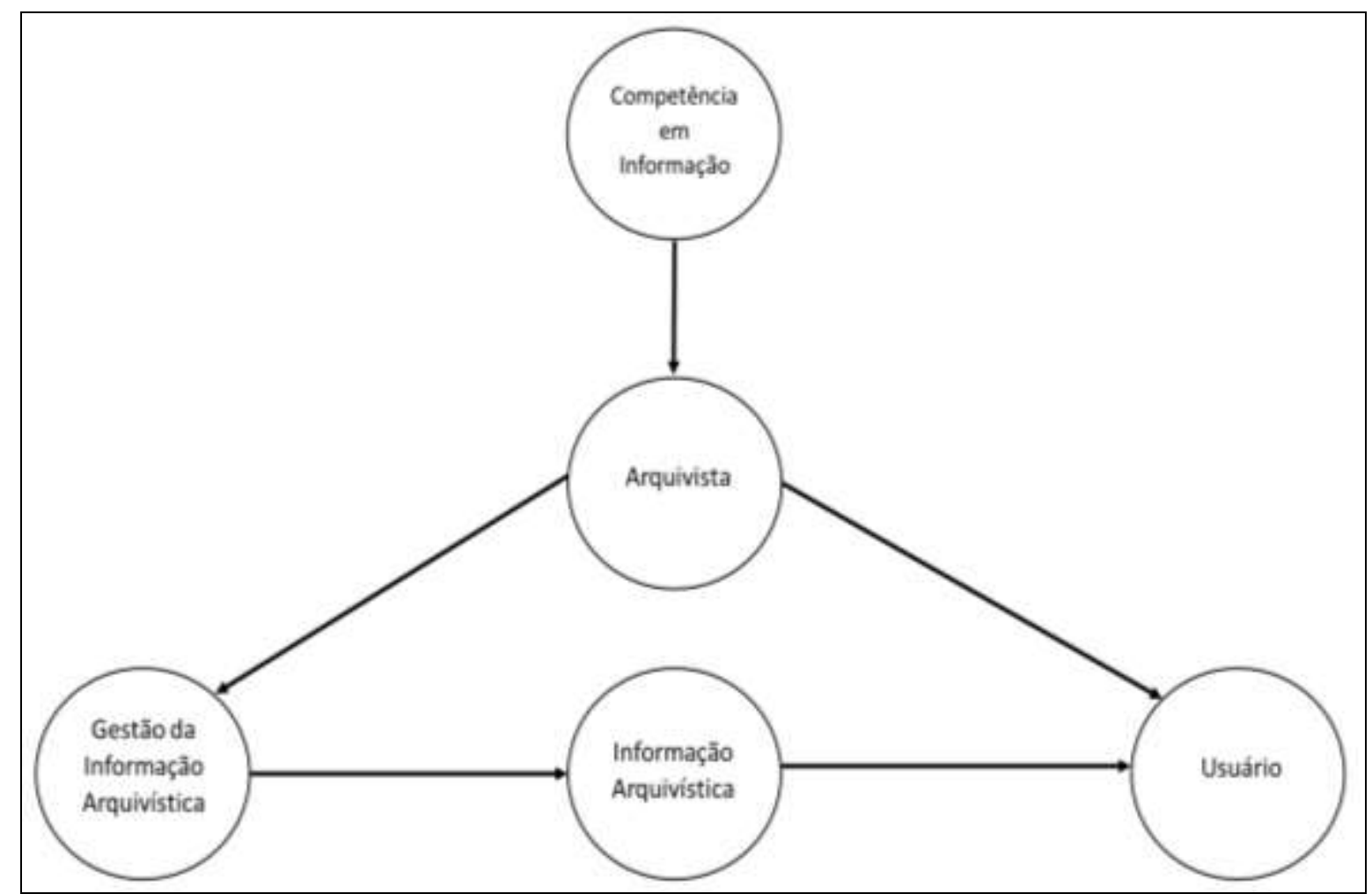

Fonte: Elaborado pelos autores (2020).

\section{Relações a partir da Gestão da Informação Arquivística}

Para apresentar as relações entre a Colnfo e a gestão da informação arquivística, elaborou-se o Decágono "Competência em Informação x Gestão da Informação Arquivística" representado pela Figura 3. O Decágono é uma figura geométrica com dez lados, na ilustração apresentada, compartimentada em Lado A e B.

O Lado A apresenta os elementos da Colnfo, sendo:

- Os cinco alicerces de Colnfo, extraídos de Ferreira (2018): necessidade da informação, recuperação da informação, análise crítica da informação, uso da informação e disseminação da informação;

- As sete habilidades para a inserção da Colnfo nas práticas arquivísticas: autonomia, criatividade, pensamento lógico, intuição, proficiência investigativa, postura ética e capacidade de resolução de problemas (FURTADO, 2019).

O Lado B apresenta os elementos da gestão da informação arquivística:

- As cinco dimensões que foram criadas a partir da conceituação, elaborada por Nascimento e Flores (2007), e das ações desenvolvidas nas atividades/funções da gestão da informação arquivística: 
I) Tratamento da informação arquivística: é um conjunto de atividades que buscam compreender o ciclo de produção da informação arquivística, ou seja, desde a sua forma abstrata até a sua destinação final.

II) Organização da informação arquivística: é um conjunto de atividades que visam estabelecer padrões de organização da informação arquivística para que a mesma possa ser facilmente recuperada.

III)Controle da informação arquivística: é um conjunto de atividades que objetivam controlar a informação arquivística para a racionalização do armazenamento e otimização da recuperação.

IV)Disponibilização da informação arquivística: é um conjunto de atividades que almejam conceder o acesso à informação arquivística disponibilizada.

V) Disseminação da informação arquivística: é um conjunto de ações que difundem a informação arquivística disponibilizada.

- As sete atividades/funções da gestão documental que compõe a gestão da informação arquivística: o diagnóstico arquivístico, a identificação arquivística, a classificação arquivística, a avaliação arquivística, a descrição arquivística, a preservação e conservação arquivística, e a difusão arquivística. (FERREIRA; MELO; 2008; SILVA, 2014; RODRIGUES, 2011; BUENO, 2011; BARROS; MORAES, 2013; SOUSA, 2003; FARIA, 2006; BERNARDES; DELATORRE, 2008; SCHELLENBERG, 2002; INDOLFO, 2012; VITAL et al., 2019; CASSARES, 2000; ROCKEMBACH, 2015; MARTENDAL, 2017; NASCIMENTO; FLORES, 2007).

Figura 3 - Decágono "Competência em informação x gestão da informação arquivística"

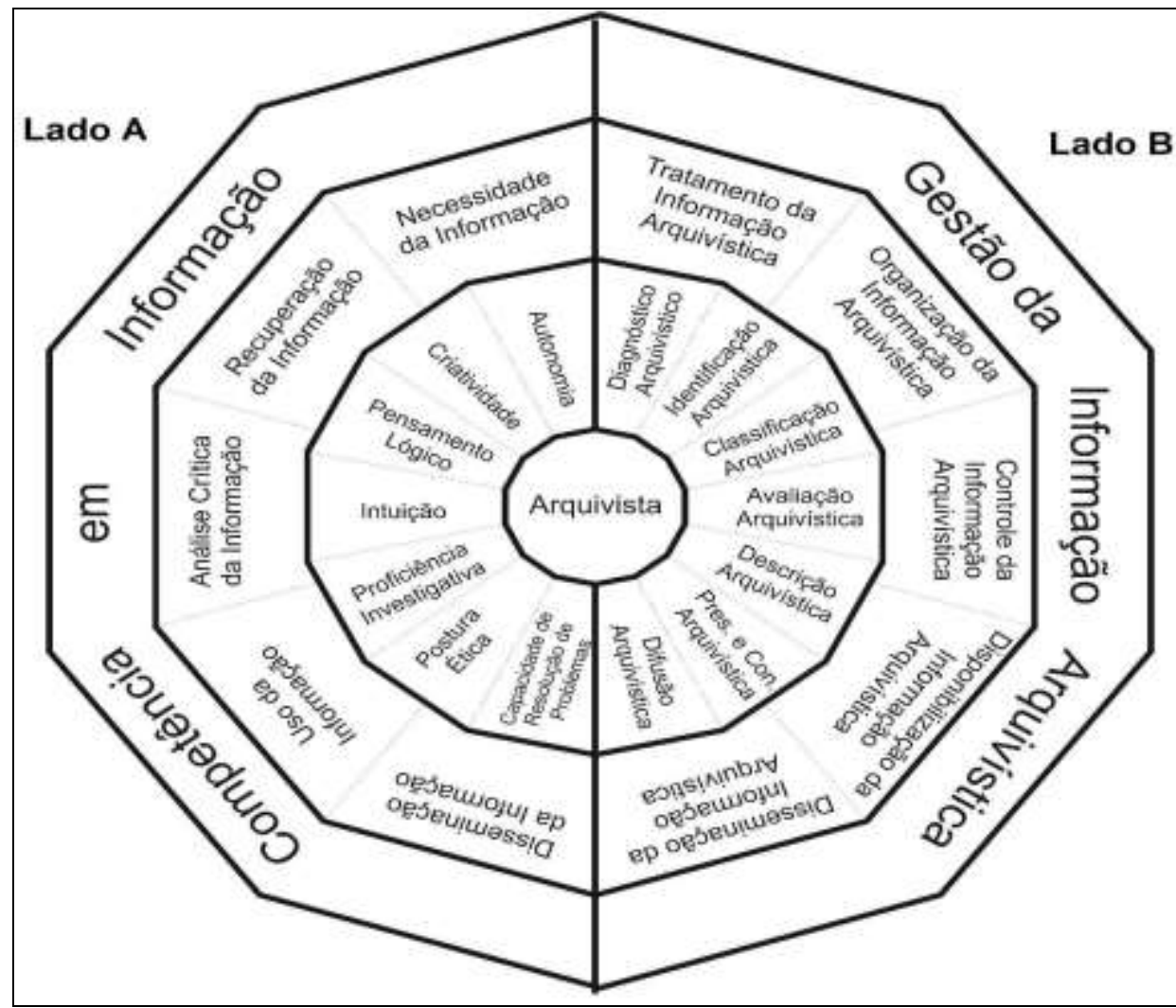

Fonte: Elaborado pelos autores (2020). 
Ao centro da Figura 3, posiciona-se o arquivista, profissional graduado em Arquivologia, que atua como mediador dos pontos de relação entre a Colnfo e a gestão da informação arquivística. Elucidados os componentes da Figura 3, a seguir estão descritas as relações entre as dimensões e atividades/funções da gestão da informação arquivística com os alicerces e habilidades da Colnfo.

A relação entre alicerces e dimensões: O processo de tratamento da informação arquivística faz com que se identifique a necessidade da informação, que embasará a definição de estratégias e métodos da recuperação da informação, que ao ser recuperada passará ao processo de organização e posteriormente deverá ser controlada, visto o grande volume de informações produzidas e recebidas mediante o looping de evolução das TICs e da difícil tarefa de buscar a autenticidade e confiabilidade das mesmas, sendo a análise crítica da informação uma importante ferramenta para que haja um melhor controle de qualidade da informação arquivística disponibilizada e disseminada para que não se torne uma fonte represada e desconhecida.

A relação entre as habilidades e as atividades/funções: Para uma melhor performance do arquivista no que tange às atividades/funções: diagnóstico, identificação, classificação, avaliação, descrição, conservação e preservação, e difusão, as habilidades elencadas para a inserção da Colnfo nas práticas arquivísticas podem tornar essa performance mais eficiente. Não se pode estabelecer uma ordem, nem mesmo uma sequência nesta descrição, entretanto, o contexto no qual serão exercidas tais atividades poderá induzir uma ordem e/ou sequência.

\section{CONSIDERAÇÕES FINAIS}

A partir da recente corrente de pesquisadores que buscam reconhecer a presença da Colnfo no âmbito arquivístico e das questões da Arquivologia pós-moderna, a presente pesquisa teve o objetivo de identificar e apresentar os elementos da Colnfo relevantes para o arquivista no contexto da gestão da informação arquivística.

Nesse cenário, as temáticas elegidas foram sistematizadas a partir da pesquisa bibliográfica, a identificação dos elementos de Colnfo e as suas relações com a gestão da informação arquivística foram denotadas por meio da análise comparativa, com isso, obteve-se como resultado quatro tipos de relações: I - Relações históricas; II - Relações a partir do usuário; III - Relações a partir do arquivista; e IV - Relações a partir da gestão da informação arquivística.

Logo, foi possível conceder tais discussões que compreendem os alicerces e as habilidades que buscam um melhor aproveitamento informacional com as dimensões e atividades/funções que buscam melhor gerir a informação arquivística, e mediadas pelo arquivista, o que resultou na Figura 3 - Decágono "Competência em informação x gestão da informação arquivística", onde tais relações estão descritas. Nisso, ressalta-se que, no âmbito arquivístico, é latente a lacuna no que tange ao desenvolvimento da gestão da informação arquivística, seu conceito atende à mudança de paradigma na Arquivologia, entretanto, a sua "corporificação" se embasa nas atividades e funções que têm o documento arquivístico como foco, estabelecendo uma relação de sinonímia.

Tal relação é desmistificada, pois quando não há a alteração do objeto, documento arquivístico para a informação arquivística, a aplicação de tais procedimentos configura uma gestão documental. A partir dessa problemática, surgem os questionamentos acerca de 
quais conceitos, procedimentos e habilidades o arquivista precisará desenvolver para resultar na gestão da informação arquivística.

Os resultados apresentados respondem à questão norteadora e o objetivo apresentado, ratificando a importância das discussões sobre Colnfo no universo arquivístico já existentes, ainda que em menor escala, e agora a inserção no contexto das práticas arquivísticas, especificamente na gestão da informação arquivística.

Cabe destacar que no desenvolvimento da pesquisa outros questionamentos surgiram acerca da díade "Colnfo - Arquivologia" e pontualmente sobre a sinonímia entre os termos gestão documental e gestão da informação arquivística. Tais problemáticas configuram-se como elementos a serem discutidos em pesquisas futuras.

\section{REFERÊNCIAS}

AMERICAN LIBRARY ASSOCIATION [ALA]. Report of the Presidential Committee on information literacy: Final Report. Chicago, 1989. Disponível em:

http://www.ala.org/acrl/publications/whitepapers/presidential. Acesso em: 06 maio 2019.

BARROS, T. H. B. A Construção discursiva em Arquivística: uma análise do percurso histórico e conceitual da disciplina por meio dos conceitos de classificação e descrição. 2010. Dissertação (Mestrado em Ciência da Informação) - Faculdade de Filosofia e Ciências, Universidade Estadual Paulista, Marília. Disponível em: http://www.marilia.unesp.br/Home/Posgraduacao/Cienciadalnformacao/Dissertacoes/barros thb me mar.pdf. Acesso em: 06 set. 2019.

BARROS, T. H. B.; MORAES, J. B. E. Da classificação biológica à classificação digital: perspectivas de renovação em classificação arquivística. Ágora, p. 58-84, 2013. Disponível em: https://agora.emnuvens.com.br/ra/article/view/426/pdf_10. Acesso em: 06 set. 2019.

BELLOTTO, H. L. Arquivos permanentes: tratamento documental. FGV editora, 2006.

BELLUZZO, R. C. B.; KERBAUY, M. T. M. Em busca de parâmetros de avaliação da formação contínua de professores do ensino fundamental para o desenvolvimento da Information Literacy. Educação Temática Digital, v. 5, n. 2, p. 129-139, jun., 2004.

BELLUZZO, R. C. B. Competência em informação: vivências e aprendizado. In: BELLUZZO, R. C. B.; FERES, G. G. (Org.). Competência em informação: das reflexões as lições aprendidas. São Paulo: FEBAB, 2013. p.58-77.

BERNARDES, I. P.; DELATORRE, H. Gestão documental aplicada. São Paulo: Arquivo Público do Estado de São Paulo, 2008. Acesso em: 04 de ago. 2019. Disponível em: http://simagestao.com.br/wpontent/uploads/2016/01/GESTAO DOCUMENTAL APLICADA I eda.pdf. Acesso em: 06 set. 2019.

BRAGA, M. M. G.; RONCAGLIO, C. Os usos do termo diagnóstico na literatura arquivística. Em Questão, v. 25, n. 1, p. 390-413, 2019. Disponível em:

https://www.seer.ufrgs.br/EmQuestao/article/view/79724. Acesso em: 18 set. 2019. 
BRASIL. Lei n. 8.159, de 08 de janeiro de 1991. Dispõe sobre a política nacional de arquivos públicos e privados e dá outras providências. Disponível em:

http://www.planalto.gov.br/ccivil 03/leis/L8159.htm\&gt. Acesso em 06 set. 2019.

CALDERON, W. R. $\mathbf{O}$ arquivo e a informação arquivística: da literatura científica à prática pedagógica no Brasil. 2011. 183 f. Tese (doutorado) - Universidade Estadual Paulista, Faculdade de Filosofia e Ciências, 2011. Disponível em: http://hdl.handle.net/11449/103375. Acesso em: 06 set. 2019.

CAMARGO, A. M. A.; BELLOTTO, H. L. (Org.). Dicionário de terminologia arquivística. São Paulo: Associação dos Arquivistas Brasileiros, 1996.

CASSARES, N. C. et al. Como fazer conservação preventiva em arquivos e bibliotecas. Arquivo do Estado, 2000.

COOK, T. Arquivologia e pós-modernismo: novas formulações para velhos conceitos. Informação arquivística, v. 1, n. 1, 2012. Disponível em:

http://www.aaeri.org.br/ojs/index.php/informacaoarquivistica/article/view/9. Acesso em: 06 set. 2019.

DUDZIAK, E. A. Information literacy: princípios, filosofia e prática. Ciência da Informação, Brasília, v. 32, n. 1, p. 23-35, 2003.Disponível em:

https://www.scielo.br/scielo.php?pid=S010019652003000100003\%20\&script=sci arttext. Acesso em: 7 ago. 2019.

DUDZIAK, E. A. Políticas de competência em informação: Leitura sobre os primórdios e a visão dos pioneiros da information literacy. In: ALVEZ, F. M. M.; CORRÊA, E. C. D.; LUCAS, E. R. O. Competência em Informação: políticas públicas, teoria e prática. políticas públicas, teoria e prática. Salvador: Edufba, 2016. p. 19-50.

FACHIN, O. Fundamentos de Metodologia. São Paulo: Saraiva, 2003.

FARIA, W. S. A normalização dos instrumentos de gestão arquivística no Brasil: um estudo da influência das resoluções do Conarq na organização dos arquivos da Justiça Eleitoral Brasileira. Dissertação (Mestrado em Ciência da Informação) - Faculdade de Economia, Administração, Contabilidade e Ciência da Informação e Documentação. Departamento de Ciência da Informação e Documentação da Universidade de Brasília (UnB), Brasília, 2006. Disponível em:

http://repositorio.unb.br/bitstream/10482/2757/1/Dissert\%20Wadson\%20Silva\%20Faria.pd f. Acesso em: 20 dez. 2020.

FARIAS, L. L. S.; FURTADO, R. L. A inserção da competência em informação nos cursos de graduação em arquivologia. ÁGORA: Arquivologia em debate, v. 30, n. 60, p. 418-434, 2020. Disponível em: https://engres.emnuvens.com.br/ra/article/view/761. Acesso em: 13 jul. 2020. 
FERREIRA, E. J. A Formação do Profissional Arquivista: a competência em informação no currículo do curso de arquivologia da UFPA. 2018. 51 f. TCC (Graduação) - Curso de Arquivologia, Universidade Federal do Pará, Belém, 2018.

FERREIRA, L. C.; MELO, D. G. P. Diagnóstico de Arquivos: Instrumento de Ação Efetiva na Gestão Documental. I Fórum Internacional de Arquivologia-UEPB-Campus V-João Pessoa, v. 25, 2008.

FORMIGA, B. K. C. Gestão de documento arquivístico em uma instituição privada. 2017. 31f. Trabalho de Conclusão de Curso (Graduação em Arquivologia) - Universidade Estadual da Paraíba, João Pessoa, 2017.

FURTADO, R. L. A competência em informação no cenário arquivístico: uma contribuição teórico-aplicada. 2019. 366f. Tese (Doutorado em Ciência da Informação) - Faculdade de Filosofia e Ciências, Universidade Estadual Paulista, Marília, 2019. Disponível em: https://repositorio.unesp.br/handle/11449/180950. Acesso em: 24 set. 2019

FURTADO, R. L.; BELLUZZO, R. C. B. Gestão do conhecimento e competência em informação: possíveis relações e perspectivas de atuação do profissional arquivista. Informação \& Informação, Londrina, v. 23, n. 2, p. 314-339, maio/ago, 2018. Disponível em: http://www.uel.br/revistas/uel/index.php/informacao/article/view/28881. Acesso em: 3 dez. 2019.

FURTADO, R. L.; BELLUZZO, R. C. B.; PAZIN, M. C. C. Arquivologia e competência em informação: possíveis conexões por meio da abordagem à literatura internacional. XIX ENCONTRO NACIONAL DE PESQUISA EM CIÊNCIA DA INFORMAÇÃO. Londrina: UEL, Anais eletrônicos... 2018. Disponível em:

http://enancib.marilia.unesp.br/index.php/XIXENANCIB/xixenancib/paper/viewFile/1352/15 31. Acesso em: 30 abr. 2019.

FURTADO, R. L.; BELLUZZO, R. C. B.; PAZIN, M. C. C. Competência em informação: disciplina necessária à formação do arquivista? Revista Acervo. Arquivo Nacional, Rio de Janeiro, 2019a. Disponível em: http://revista.arquivonacional.gov.br/index.php/revistaacervo/article/view/967. Acesso em: 22 maio 2019.

FURTADO, R. L.; BELLUZZO, R. C. B.; PAZIN, M. C. C. A Competência em informação na formação em Arquivologia. In: XVIII ENCONTRO NACIONAL DE PESQUISA EM CIÊNCIA DA INFORMAÇÃO. Marília: UNESP, 2017. Anais eletrônicos... Disponível em: http://enancib.marilia.unesp.br/index.php/xviiienancib/ENANCIB/paper/view/355. Acesso em: 30 abr. 2019

FURTADO, R. L.; BELLUZZO, R. C. B.; PAZIN, M. C. C. Competência em informação e Arquivologia: relato de pesquisa. In: BARRO, T. H. B.; SANTOS JÚNIOR, R. L.; CÂNDIDO, G. G. A pesquisa e o ensino em Arquivologia: perspectivas na era digital. Volume 1. p. 69-78. Ed.UFPA. 2019c. Disponível em: https://lume.ufrgs.br/handle/10183/202102. Acesso em 20 jan. 2020. 
FURTADO, R. L.; BELLUZZO, R. C. B.; PAZIN, M. C. C. Competência em informação e Arquivologia: uma revisão bibliográfica sistemática no cenário nacional e internacional. In: XVII Encontro Nacional de Pesquisa em Ciência da Informação (XVII ENANCIB), 2016, Salvador.

Anais Enancib 2016 - Descobrimentos da Ciência da Informação. Desafios da Multi, Inter e Transdisciplinaridade. Salvador: PPGCI - UFBA, 2016. p. 1473-1492. Disponível em:

http://www.ufpb.br/evento/index.php/enancib2016/enancib2016/paper/view/3959. Acesso em: 22 jun. 2019.

FURTADO, R. L.; BELLUZZO, R. C. B.; PAZIN, M. C. C. A Competência em Informação na Arquivologia: reflexões sob o enfoque da pesquisa. In: A Pesquisa e o Ensino em Arquivologia:

Perspectivas na Era Digital. Volume 1. p. 304-314. Ed.UFPA. 2019b. Disponível em:

https://lume.ufrgs.br/handle/10183/202102. Acesso em 20 jan 2020

FURTADO, R. L.; FERREIRA, E. J. A Competência em Informação no currículo do curso de Arquivologia da Universidade Federal do Pará. Biblionline, João Pessoa, v. 15, n. 1, p. 107-121 , 2019. Disponível em:

http://www.periodicos.ufpb.br/ojs2/index.php/biblio/article/view/44454. Acesso em: 23 jun. 2019.

FURTADO, R. L.; SILVA, V. M. O papel do Arquivista na defesa dos direitos humanos: em busca de elementos da Competência em Informação. Convergências em Ciência da Informação, v. 2, n. 2, p. 23-43, 2019. Disponível em:

https://seer.ufs.br/index.php/conci/article/view/11782. Acesso em: 13 jan. 2020.

INDOLFO, A. C. Avaliação de documentos de arquivo: atividade estratégica para a gestão de documentos. Revista do Arquivo Geral da Cidade do Rio de Janeiro, Rio de Janeiro, v. 6, p. 13-37, 2012. Disponível em: http://wpro.rio.ri.gov.br/revistaagcri/wpcontent/uploads/2016/11/e06 a15.pdf. Acesso em: 21 fev. 2019.

INDOLFO, A. C. Gestão de documentos: uma renovação epistemológica no universo da arquivologia. Arquivística.net, Rio de janeiro, v. 3, n. 2, p. 28-60, 2007. Disponível em: https://brapci.inf.br/index.php/res/v/50444. Acesso em: 30 jan. 2019.

JARDIM, J. M. O conceito e a prática de gestão de documentos. Acervo, Rio de Janeiro, v. 2, n. 2, p. 35-42, 1987. Disponível em: http://simagestao.com.br/wpcontent/uploads/2016/02/O-Conceito-e-a-Pratica-de-Gestao-de-Documentos.pdf. Acesso em: 19 jan. 2019.

MARTENDAL, F. F. A difusão da informação arquivística e suas expressões no ensino de arquivologia no brasil. Formación Archivística, 2017. Disponível em: http://redarchiveroscordoba.com/wp-content/uploads/2017/10/TOMO-IV.pdf\#page=120. Acesso em: 27 out. 2019.

MARTENDAL, F. F.; SILVA, E. C. L.; VITORINO, E. V. Diálogo entre as dimensões da competência em informação e os cursos de graduação em Arquivologia do sul do Brasil. Em questão, v. 23, n. 3, p. 53-78, 2017 Disponível em: https://seer.ufrgs.br/EmQuestao/article/view/69952. Acesso em: 13 ago. 2019. 
MOURA, A. R. P.; FURTADO, R. L.; BELLUZZO, R. C. B. Desinformação e competência em informação: discussões e possibilidades na Arquivologia. Ciência da Informação em Revista, v. 6, n. 1, p. 37-57, 2019. Disponível em:

http://www.seer.ufal.br/index.php/cir/article/view/7063. Acesso em: 13 jun. 2019.

MORENO, N. A. A informação arquivística e o processo de tomada de decisão. Informação \& Sociedade, v. 17, n. 1, 2007. Disponível em:

https://periodicos.ufpb.br/ojs/index.php/ies/article/view/483. Acesso em: 17 set. 2019

OTLET, P. Documentos e documentação. Paris, 1937.

PAES, M. L. Arquivo: teoria e prática. 3, Ed. Rio de Janeiro: FGV, 2004.

ROCKEMBACH, M. Difusão em arquivos: uma função arquivística, informacional e comunicacional. Informação Arquivística, v. 4, n. 1, 2015. Disponível em:

http://www.aaerj.org.br/ojs/index.php/informacaoarquivistica/article/view/95. Acesso em: 12 ago. 2019.

RONDINELLI, Rosely Curi. $O$ conceito de documento arquivístico frente à realidade digital: uma revisão necessária. Editora FGV, 2011.

ROUSSEAU, J.-Y.; COUTURE, C.; ARÈS, F. Os fundamentos da disciplina arquivística. Lisboa: Publicações Dom Quixote, 1998.

SANTOS, P. R. E. Arquivística no laboratório: história, teoria e métodos de uma disciplina. Rio de Janeiro: Teatral, 2010.

SCHELLENBERG, T. R. Arquivos modernos. FGV Editora, 2002.

SCHNEIDER, S.; SCHIMITT, C. J. O uso do método comparativo nas Ciências Sociais. Cadernos de Sociologia, Porto Alegre, v. 9, p. 49-87, 1998. Disponível em: http://nc-

moodle.fgv.br/cursos/centro rec/docs/o uso metodo comparativo.pdf. Acesso em: 10 set. 2019.

SILVA, S. C. A. A preservação da informação. Revista Cadernos do Ceom, v. 18, n. 22, p. 177190, 2014.

SOUSA, R. T. B. Os Arquivos correntes no contexto das três idades documentais. 2007. Disponível em:

http://www.cid.unb.br/publico/setores/000/84/materiais/2007/1/532/M\%C3\%B3dulo2.doc . Acesso em: 06 set. 2019.

SOUSA, R. T. B. Os princípios arquivísticos e o conceito de classificação. 2003. Disponível em: https://core.ac.uk/download/pdf/33529652.pdf. Acesso em: 19 jul. 2019.

TOGNOLI, N. B. A informação no contexto arquivístico: uma discussão a partir dos conceitos de informação-como-coisa e informação orgânica. Informação Arquivística, p. 113-122, 
2012. Disponível em:

http://www.aaerj.org.br/ojs/index.php/informacaoarquivistica/article/view/8. Acesso em: 27 out. 2019

TORRES, M. R. L. C. Gestão da Informação aplicada aos processos de trabalho do IBAMA. 2019. 160 f. Tese (Doutorado) - Curso de Ciência da Informação, Universidade Federal de Pernambuco, Recife, 2019. Disponível em:

https://repositorio.ufpe.br/handle/123456789/33767. Acesso em: 20 out. 2019

VITAL, L. P. et al. Descrição arquivística e contextualização: experiência com o acervo de Sebastião Salgado. Informação em Pauta, Fortaleza, v. 4, n. 1, p. 29-47, jan./jun. 2019. DOI: https://doi.org/10.32810/25253468.ip.v4i1.2019.39919.29-47. Acesso em: 20 out. 2019.

VITORIANO, M. C. C. P. A relação entre gestão da informação e gestão documental na arquivologia: mapeamento do tema em publicações científicas brasileiras. Palabra Clave, La Plata, v. 7, n. 1, p.38-55, out. 2017a. Disponível em: http://eprints.rclis.org/32478/1/e038.pdf. Acesso em: 23 out. 2019.

VITORIANO, M. C. C. P. Uma aproximação entre Arquivologia e Ciência da Informação: o uso dos conceitos de informação orgânica e informação arquivística. Brazilian Journal of Information Science, [Marília], v. 11, n. 4, p. 57-66, 2017b. Disponível em:

https://revistas.marilia.unesp.br/index.php/bjis/article/view/7509. Acesso em: 23 fev. 2019. 